\title{
Isolation of Biosurfactant from Lactobacillus sp. and Study of Its Inhibitory Properties Against E.coli Biofilm
}

\author{
E.S. Challaraj Emmanuel*, S. Sree Priya and Sona George \\ Department of Life Sciences, Kristu Jayanti College (Autonomous), K. Narayanapura, Kothanur Post, \\ Bengaluru - 560 077, Karnataka, India.
}

\begin{abstract}
Bacteria are ubiquitous in nature, survive in all environment by forming biofilm on any suitable substrata. Biofilms can harbor human infectious agents in the environment as well in the human body. E.coli is a most important species that is found in the human gastrointestinal tract and has the ability to form biofilm both In vivo and In vitro. Biosurfactants play a significant role in biotechnology for industrial and medical applications. The surface hydrophobicity is modified by the adsorption of biosurfactants, thus interferes in the microbial binding and desorption processes. The production of biosurfactants by probiotic bacteria in vivo acts as a defense weapon against most troublesome pathogenic strains in the urogenital and gastrointestinal tracts and on medical devices. The biosurfactant shows promising results than the chemical surfactant as they are better biodegradable and do not pollute the environment. Lactobacillus is a probiotic bacterium which is recognized as potential interfering bacteria by producing various antimicrobial agents. In the current study, biosurfactant producing Lactobacillus $s p$. isolated from homemade curd sample. The TLC result indicates that it is a lipopeptide biosurfactant. The FTIR analysis predominantly shows the presence of alkene and alkyne groups. The antimicrobial activity of biosurfactant against E.coli is compared with different concentrations of chemical surfactant SDS and the results indicate a similar antimicrobial activity. The biofilm inhibition assays suggest that the biosurfactant produced by Lactobacillus inhibits the biofilm of $E$. coli.
\end{abstract}

Keywords: Lactobacillus, Probiotic, biosurfactant, biofilm.

*Correspondence: challaraj.e@kristujayanti.com

(Received: 04 September 2018; accepted: 04 January 2019)

Citation: E.S. Challaraj Emmanuel, S. Sree Priya and Sona George, Isolation of Biosurfactant from Lactobacillus sp. and Study of Its Inhibitory Properties Against E. coli. Biofilm, J Pure Appl Microbiol., 2019; 13(1):403-411 doi: 10.22207/JPAM.13.1.44

(c) The Author(s) 2019. Open Access. This article is distributed under the terms of the Creative Commons Attribution 4.0 International License which permits unrestricted use, sharing, distribution, and reproduction in any medium, provided you give appropriate credit to the original author(s) and the source, provide a link to the Creative Commons license, and indicate if changes were made. 


\section{INTRODUCTION}

A biofilm is a collection of microbial cells that is permanently related with a surface and enclosed in a matrix of predominantly polysaccharide material, depending on the environment. Zobell (1943) observed that the solid-liquid interface between a surface and an aqueous medium provides a model atmosphere for the attachment and growth of microorganisms. The examination of biofilm by scanning and transmission electron microscopy on trickling filters in a wastewater treatment plant by Jones et al., (1969) showed that the biofilms are composed of a variety of organisms. Biofilms forms on almost all types of surfaces, as well as living tissues, indwelling medical devices, industrial or potable water system piping, or natural aquatic systems. Characklis et al., (1973) noted that the level of microbial colonization appears to upsurge as the surface roughness surges. Biofilms are composed mainly of microbial cells and EPS (Flemming et al., 2000). EPS could account for $50 \%$ of the total organic carbon of biofilms and might be thought of the first matrix material of the biofilm. Even though that the EPS may vary in physiochemical properties, it is chiefly composed of polysaccharides.In most of the gram negative bacteria the polysaccharides in EPS are neutral or polyanionic. The presence of uronic acids (such as D-glucuronic, D-galacturonic, and mannuronic acids) or ketal-linked pryruvates are attributed to the anionic property of EPS. (Sutherland, 2001).

Escherichia coli may be a predominant species among facultative anaerobic bacterium of the channel. A good array of genetic tools contributed to ascertain E. coli as a relevant model organism for the study of surface organization. Many key factors, as well as completely different living thing appendages in $E$. coli facilitate them for surface organization. Both in space and time the expression and activity were finely regulated, to confirm productive events resulting in mature biofilm formation. Though current data of bacteriology owes a lot of to figure done on being cultures of laboratory strains of $\mathrm{E}$. coli, several isolates even have the capability to create biofilm structures in vivo and in vitro (Probert and Gibson, 2002). E. coli biofilm development may be an advanced method that results in advanced structures that square measure vital for its pathological process and for engineering applications (Jayaraman et al., 1999).

Biosurfactants are classes of compounds called surface-active compounds (or surfactants) that decrease prominently the interfacial tension or interfacial free energy of the interfaces have several applications in agriculture, medicine, petroleum and industry. The amphiphilic nature of the biosurfactans are due to the hydrophilic and hydrophobic regions. The surfactants have a affinity to accumulate at the interface of immiscible fluids with decrease in free energy that is reflected during a corresponding lowering of surface tension that assists emulsification of the immiscible fluids and thence such compounds also are referred to as emulsifiers. Most work on biosurfactant applications has been centered on their use in environmental applications attributable to their diversity, property and production on largescale and environmental friendly nature. Some biosurfactants are appropriate alternatives to artificial medicines and antimicrobial agents and can also be used as safe and effective therapeutic agents.

Lactobacilli, probiotic bacteria, have a positive effect on the maintenance of human health. These bacteria are commensals, and protect human beings by producing various antimicrobial agents such as organic acids, hydrogen peroxide, carbon peroxide, diacetyl, antimicrobial substances of lower molecular weight, bacteriocins, and adhesion inhibitors, such as biosurfactants (Gupta and Garg, 2009). In particular, Lactobacilli is known for its antimicrobial activity and capability to interfere with the pathogens adhesion on epithelial cells of urogenital and intestinal tracts and for their antibiofilm production on catheter devices (Hawthorn and Reid, 1990) and voice prostheses (Rodrigues et al., 2006). The biosurfactants play an important role in interference of pathogens (Velraeds et al., 1996).

\section{MATERIALS AND METHODS}

\section{Isolation and Characterization of Lactobacillus}

Lactobacillus was isolated by serial dilution technique from home-cured curd samples and was plated onto pre sterilized MRS (Man, Rogosa and Sharpe) agar plates. Then the plates were incubated at $37^{\circ} \mathrm{C}$ for $24 \mathrm{~h}$. Then the colonies 
with completely different morphology, color and dimension were selected and sub-cultured on recent MRS agar plates. The organism for biofilm production was obtained from domestic sewage sample. The human infective gram negative bacterium Escherichia coli was isolated and confirmed by culturing on (EMB Agar) Eosin methylene blue agar.

The selected colonies were identified supported morphological and biochemical characteristics. The morphological characteristics like colony size, surface, opacity, color, motility and cell shape were discovered and gram staining was performed. Biochemical characteristics like Indole production, methyl Red, Vogues Proskauer, Citrate, Catalase, Oxidase, Starch reaction and Casein degradation were performed (Holt et al., 1994).

Amplification and sequencing of 165 rRNA sequence analysis:

Genomic deoxyribonucleic acid was extracted as per Ausubel et al., (1988). 16S rRNA genes of the microorganism isolates were amplified with genomic deoxyribonucleic acid isolates as sequence templates and $8 \mathrm{~F}$ and $1490 \mathrm{R}$ primers every reaction mixture contained $2 \mu \mathrm{l}$ of template deoxyribonucleic acid (100 ng), $0.5 \mu \mathrm{M}$ of 2 primers, and $25 \mu \mathrm{l}$ of accelerator Master combine (Bioron). The PCR program consisted of associate initial denaturation step at $94^{\circ} \mathrm{C}$ for five min, followed by thirty cycles of deoxyribonucleic acid denaturation at $92^{\circ} \mathrm{C}$ for thirty sec, primer hardening at $50^{\circ} \mathrm{C}$ for one min, and primer extension at $72^{\circ} \mathrm{C}$ for two min was administered in Thermal Cycler (ThermoHybaid). The PCR end products were refined by QIAquick PCR purification kit and cloned with QIAGEN PCR biological research kit. Clones were identified and isolated, plasmids with insert were sequenced with M13 Sequencing Primers in ABI Biosystems automatic sequencer. Nucleotide database was searched with the sequences obtained with NVBI BLAST (Blastn) tool (http://www/ncbi.nlm.nih.gov/ BLAST) (Altschul et al., 1997).

\section{Biosurfactant Production}

A starter culture of $20 \mathrm{ml}$ MRS broth was prepared with Lactobacillus and incubated for $24 \mathrm{~h}$ at $28^{\circ} \mathrm{C}$ in static condition. After $24 \mathrm{~h}$ of incubation the $20 \mathrm{ml}$ broth starter culture was inoculated into $1000 \mathrm{ml}$ broth and incubated at $28^{\circ} \mathrm{C}$ for 24 h. After incubation, the cells were removed by centrifugation at $8000 \mathrm{rpm}$ for 30 minutes. The supernatant was collected.

\section{Screening tests for Biosurfactant}

$1 \mathrm{ml}$ of oil (motor oil) was added on the surface $20 \mathrm{ml}$ of distilled water in a petriplate, and $0.5 \mathrm{ml}$ of supernatant was added to the surface of oil. Formation of a clear zone is the indication of biosurfactant presence in the supernatant. The diameter of the zone was measured.

\section{Determination of emulsification index}

$2 \mathrm{ml}$ sample of the cell free supernatant was taken in a small test tube along with $2 \mathrm{ml}$ of oil (petrol). To ensure homogenous mixing of both the lipids, the mixture was vortexed at high speed for 2 minutes and incubated at RT for $24 \mathrm{~h}$. The emulsification index $\left(E_{24}\right)$ was calculated by dividing the measured height of the emulsification layer by the mixtures total height and multiplying by 100 . (Anayata Sharma et al., 2014).

$$
\text { E24 }=\frac{\text { Total height of emulssion }}{\text { Total height of the aqueous layer }} \times 100
$$

\section{Drop collapse test}

$25 \mu \mathrm{l}$ of biosurfactant was pipetted as a droplet onto a parafilm, the spreading of the droplet on the parafilm was observed. Similarly $25 \mu \mathrm{l}$ of water was pipetted on a parafilm and the changes were observed. The biosurfactant spreads and get flattened whereas water stays intact without any change. (Arezoo Tabmourespour et al., 2011).

Isolation, Extraction and Purification of Biosurfactant

The supernatant after centrifugation was collected and the $\mathrm{pH}$ was adjusted to 2.0 using 6 $\mathrm{N} \mathrm{HCL}$ and kept at $4^{\circ} \mathrm{C}$ overnight. Equal amount of Chloroform: Methanol (2:1) mixture was added to the supernatant, vigorously mixed and kept overnight for phase separation. The mixture forms 3 layers - lower layer is the chloroform: methanol, middle layer is the biosurfactant and upper layer is the supernatant (Abdullahi Adamu et al., 2015). The biosurfactant formed (middle layer) was carefully taken out with the help of a micropipette and was transferred to microfuge tubes. $1 \mathrm{ml}$ of distilled water was added to the microfuge tube containing biosurfactant and was thoroughly vortexed. This mixture was centrifuged at 7000 rpm for 30 minutes at $4 \mathrm{C}$. The supernatant was discarded and the pellet obtained was allowed to 
dry for $24 \mathrm{~h}$.

Analysis and Identification of Biosurfactant Thin Layer Chromatography (TLC)

The identification of the bioactive compound present in the biosurfactant was screened by Thin Layer Chromatography (TLC). Silica coated plates were prepared and the pelleted crude biosurfactant obtained was spotted onto the plate. The solvent used for separation was chloroform: water: methanol (65:24:4). Ninhydrin reagent was sprayed over it and the appearance of red spots indicates the presence of lipopeptide in the biosurfactant. (Anayata Sharma et al., 2014). FTIR analysis of biosurfactant

To demonstrate the functional groups of the bioactive compound within the biosurfactant, the pellet was analyzed by Fourier transform infrared spectroscopy (FTIR) (Ragavendran et al., 2011). The spectrum for knowing the functional groups dominating within the samples was done by using model Perkin Elmer Spectrum Version 10.03.07 (Courtesy: Bangalore Testing laboratory Pvt. Ltd.) NDXUS-672. The spectrum was taken in a very mixed IR $400-4000 \mathrm{~cm}^{-2}$ with 16 scan speed and was recorded in an Attended total reflectometer (ATR)

\section{Antimicrobial Activity of Biosurfactant}

A total of 9 plates were used and all the plates were swabbed with Escherichia coli on MHA (Muller Hinton Agar) plates. In four plates, two wells were made and labelled as 1 and 2 respectively. To the well labelled 1 , purified biosurfactant was added and to the well labelled 2, different concentrations of SDS (sodium dodecyl sulphate) $-0.1 \%, 0.5 \%, 1 \%, 1.5 \%$ were added in order to compare the action of biosurfactant against chemical surfactant. To the remaining 5 plates, one well was made for each them, for which three plates were crude biosurfactant, for the last two plates, one was supernatant and the other was MRS broth which served as negative control. A clear zone around the wells indicates the antimicrobial activity of biosurfactant (Anayata Sharma et al., 2014). The results were tabulated and analyzed.

Inhibition Study on Biofilm Formation Air Liquid Interphase Coverslip Assay

E.coli was cultivated with LB medium in six Erlynmeyer flasks (50 ml). Sterile cover slips were added to the broth culture and incubated at $37^{\circ} \mathrm{C}$ for $24 \mathrm{~h}$. After incubation, the cover glass was taken out from one flask which serves as the control and stained with crystal violet for 1 minute and observed under microscope at $40 x$ magnification to check for the presence of biofilm. Later the coverslips were treated with biosurfactant at different concentrations (10\%, 20\%, 30\%, 40\%, 50\% v/v) for $6 \mathrm{~h}$ at room temperature. After incubation, the cover glass was taken out and washed with distilled water and stained with crystal violet for 1 minute. Under $40 \mathrm{X}$ objective the action of biosurfactant on the bifolm was bserved using a microscope (Pratt et al., 1999).

\section{Biofilm Inhibition Assay}

Overnight culture of E.coli was inoculated in to six microfuge tube containing $0.5 \mathrm{ml}$ of LB broth and $0.5 \mathrm{ml}$ of different concentrations of biosurfactant (10\%, 20\%, 30\%, 40\%, 50\% v/v) were added to 5 microfuge tubes and 1 microfuge tube served as a control without biosurfactant. The tubes were incubated for $48 \mathrm{~h}$ at $37^{\circ} \mathrm{C}$, later 0.1 $\mathrm{ml}$ crystal violet was added to all the microfuge tubes and exposed for 5 minutes. Following which the stain was discarded and the microfuge tubes were rinsed twice with distilled water. Then the microfuge tubes were allowed to dry and the activity of biosurfactant was observed based on the colour intensity of crystal violet on the microfuge tube.

\section{RESULTS AND DISCUSSION}

The biosurfactant producing Lactobacillus strain was isolated from homemade curd sample and confirmed by its morphological and biochemical characteristics (Table 1). (Table 2). After gram staining, the biochemical tests were performed. The DNA was isolated and its molecular characterization was done using DNA sequencing technique. The strain was used for isolation and extraction of biosurfactant (Table 3). The isolated organism was subjected for different screening techniques to check for the production of biosurfactant. The biosurfactant extracted from Lactobacillus displaced oil and formed a clear zone in the center of the plate and the diameter of the clear zone formed was measured as $2 \mathrm{~cm}$ (Fig. 1).

The emulsification index of the biosurfactant was evaluated against substrate as petrol. The emulsification index $\left(\mathrm{E}_{24}\right)$ obtained was 
Table 1. Biochemical characteristics of the isolate

\begin{tabular}{lcl}
\hline S. No. & Tests performed & Observations \\
\hline 1. & Indole & Negative \\
2. & Methyl red & Positive \\
3. & Vogues Proskauer & Negative \\
4. & Citrate & Negative \\
5. & Catalase & Negative \\
6. & Oxidase & Negative \\
7. & Starch hydrolysis & Positive \\
8. & Casein hydrolysis & Positive \\
\hline
\end{tabular}

Table 2. Morphological characteristics of the isolate

\begin{tabular}{lll}
\hline S. No. & $\begin{array}{l}\text { Morphological } \\
\text { characteristics }\end{array}$ & Observations \\
\hline 1. & Surface & Smooth, creamy \\
2. & Opacity & Translucent \\
3. & Colour & Off white \\
4. & Motility & Non motile \\
5. & Gram staining & Positive \\
6. & Cell shape & Rods \\
\hline
\end{tabular}

$58.1 \%$. The good emulsifying property is critical for biosurfactants to be promising in different environmental and industrial applications. The criteria for determining the emulsion-stabilizing capacity of an emulsifier is its ability to maintain at least $50 \%$, after $24 \mathrm{~h}$ of its formation (Willumsen and Karlson, 1997). Considering this fact that the biosurfactant produced from the isolate had a good emulsifying capacity as its emulsification index value is more than $50 \%$. The droplet size of biosurfactant measured was $1 \mathrm{~mm}$ larger than the one produced by distilled water. Hence, the biosurfactant droplet resulted in a collapsed droplet which indicates its effect on reduction of surface tension. A mixture is formed after the addition of equal amount of chloroform: methanol (2:1) in which the middle layer formed is the biosurfactant which is separated out for further purification after overnight evaporation. The thickness of the middle layer was measured as $5 \mathrm{~mm}$. The layer was carefully separated out in

Table 3. Molecular Identification of the isolate.

\begin{tabular}{lcc}
\hline S. No. & BLAST results & Gen Bank accession No. \\
\hline 1. & Lactobacillus sp., & KX098332
\end{tabular}

to a microfuge tube and purified by centrifugation at 7000rpm for 10 minutes using distilled water. After centrifugation, a white colored pellet was obtained which was the crude biosurfactant. The pellet was dried and weighed. The crude biosurfactant was measured as $3.21 \mathrm{gram}$. The identification of the bioactive compound present in the biosurfactant was done by Thin Layer Chromatography. The Rf (Retardation factor) value was 0.82 . The appearances of red colored spots on the TLC plate indicate the presence of lipopetide in the biosurfactant. According to the $R_{f}$ value, the compound present in the biosurfactant produced was found to be tryptophan.

The graph indicates the presence of alkene, alkyne group and conjugated di-ene in the surfactant which indicates higher surface activity (Fig. 2). Alkene and alkyl benzene components of surfactant are being significantly most effective surfactants. New anionic surfactants are derived from aromatic or substituted aromatic molecules and alkenes. Peaks at $1500-1650 \mathrm{~cm}^{-1}$ indicates the presence of $\mathrm{C}=\mathrm{C}$ alkene component (Table 4 ). This

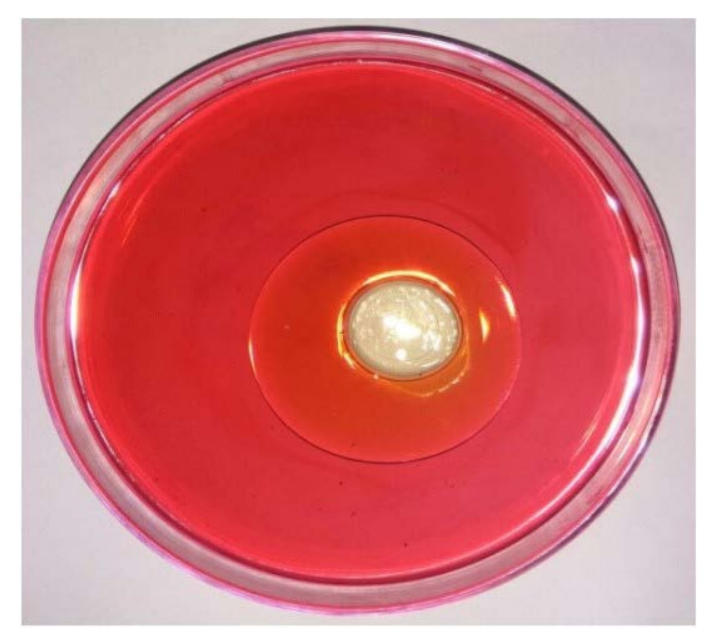

Fig. 1. Oil spread technique showing zone of clearance

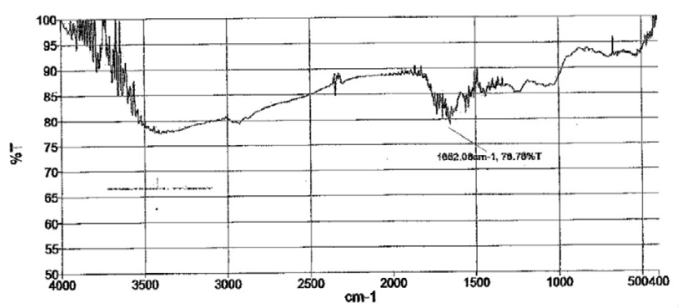

Fig. 2. FTIR - spectrum of Biosurfactant 
Table 4. Analysis of FTIR spectrum (Biosurfactant)

\begin{tabular}{lccc}
\hline S. No. & Wavelength $\left(\mathrm{cm}^{-1}\right)$ & $\%$ of transmission & Functional groups \\
\hline 1. & 1652 & $80 \%$ (weak) & $\mathrm{C}=\mathrm{C}$ (alkene group) \\
2. & $2001-2500$ & $85 \%$ (strong) & $\mathrm{Ca} \equiv \mathrm{C}$ (alkyne group) \\
\hline
\end{tabular}

reveals the surfactant extracted from the organism shows maximum similarity to the formulated anionic sulphonate surfactants having higher surface tension activity and good emulsification index (Tuvell et al., 1978)

This present study was conducted to check the antimicrobial activity of the biosurfactant produced by Lactobacillus against pathogenic E.coli. The antimicrobial activity of biosurfactant produced was compared against chemical surfactant also viz., SDS (sodium dodecyl sulphate) at different concentrations $(0.1,0.5,1,1.5 \%)$. The zone of inhibition was observed for Biosurfactant confirming their antimicrobial activity against E.coli. The same study was carried out E.coli using MRS broth as the negative control (Table 5). The results observed were; Negative control showed no antimicrobial activity against E.coli. The biosurfactant showed comparatively higher antimicrobial activity than the supernatant. The antimicrobial activity of SDS against E.coli was compared (Table 6) with the zone of inhibition shown by biosurfactant, which is measured as 1.1 , $1.0,1.2,1.2 \mathrm{~cm}$ respectively.

In this graph, it was observed that crude biosurfactant showed higher antimicrobial activity against E.coli than SDS at all the different concentrations (Figs. 3 \& 4). Firstly, average values of zone of inhibition of SDS at each concentration are plotted along with values of crude biosurfactant. Biofilm of E.coli was allowed to form on a coverslip and the action of biosurfactant in different concentrations on the biofilm was tested. The microscopic examination of the coverslip after $6 \mathrm{~h}$ of biosurfactant treatment showed that the number of E.coli cells decreased as the concentration of biosurfactant increased. The coverslip which served as control showed a uniform distribution of E.coli cells with a dense population. The coverslip which was treated with $10,20,30,40,50 \% \mathrm{v} / \mathrm{v}$ of biosurfactant was observed with a decrease in population of E.coli cells (Fig. 5). For tube test, the biosurfactant at different concentrations $(10,20,30,40,50 \%$ $\mathrm{v} / \mathrm{v}$ ) was added along with the E.coli culture to grow for $48 \mathrm{~h}$ (Fig. 6). Two microfuge tubes were maintained as positive and negative control. The

Table 5. Antimicrobial activity of biosurfactant

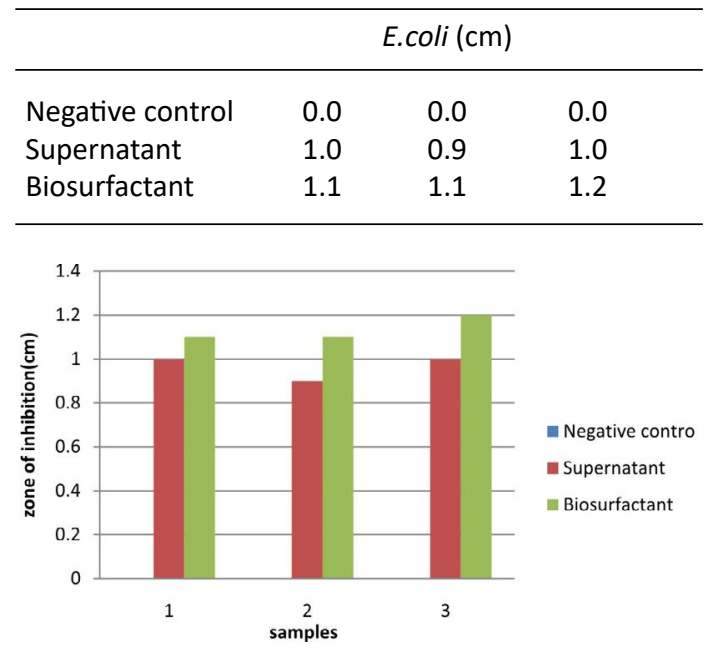

Fig. 3. Graph showing comparison of antimicrobial activity of biosurfactant against $E$. coli

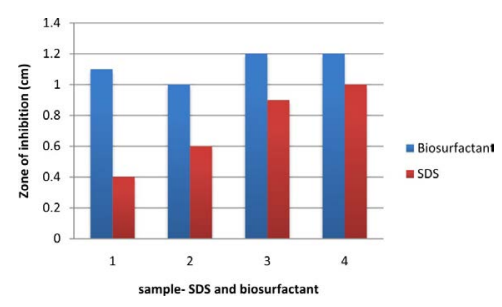

Fig. 4. Comparison of antimicrobial activity of biosurfactant with SDS.

Table 6. Antimicrobial activity of SDS against E.coli at different concentrations.

\begin{tabular}{llll}
\hline SDS(\%) & \multicolumn{3}{c}{$\begin{array}{c}\text { E.coli } \\
\text { Diameter of Zone of inhibition }(\mathrm{cm})\end{array}$} \\
\hline $0.1 \%$ & 0.4 & 0.6 & 0.4 \\
$0.5 \%$ & 0.6 & 0.6 & 0.8 \\
$1.0 \%$ & 0.8 & 0.9 & 1.0 \\
$1.5 \%$ & 1.0 & 1.0 & 1.1 \\
\hline
\end{tabular}




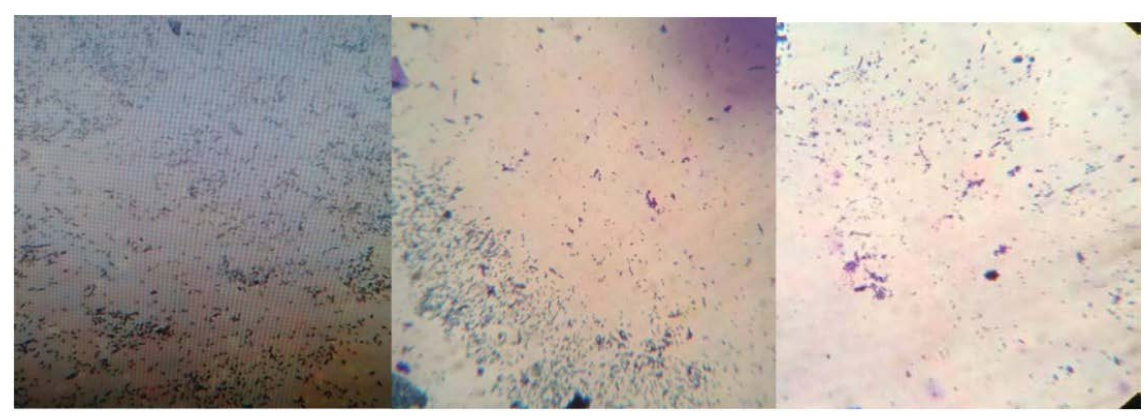

$10 \% \mathrm{v} / \mathrm{v}$ biosurfactant $20 \% \mathrm{v} / \mathrm{v}$ biosurfactant $30 \% \mathrm{v} / \mathrm{v}$ biosurfactant

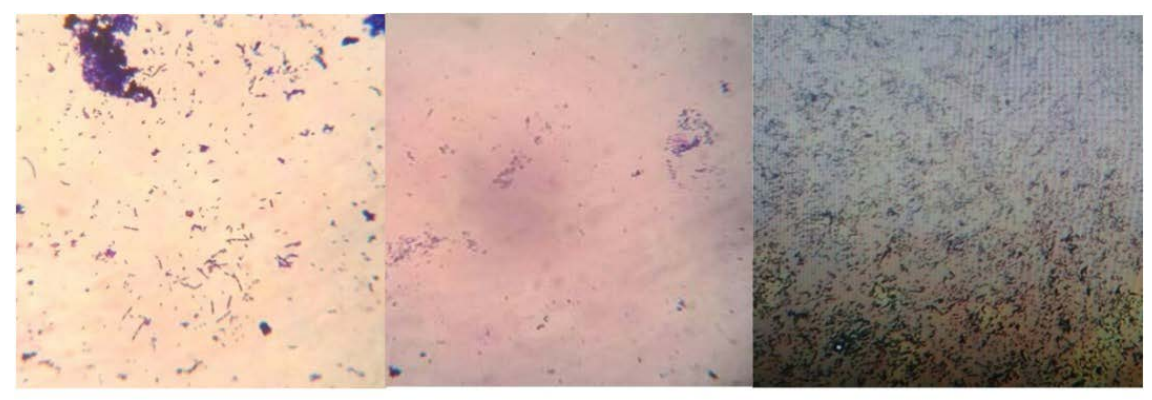

$40 \% \mathrm{v} / \mathrm{v}$ biosurfactant $50 \% \mathrm{v} / \mathrm{v}$ biosurfactantcontrol

Fig. 5. Air liquid interphase coverslip assay

positive control was not treated with biosurfactant and the negative control tube was only subjected to staining. The reduction in the biomass formed on biofilm was noticed on the microscopic image as the concentration of the bioactive compound increased.

In the present study, Lactobacillus was isolated with biosurfactant producing ability. The identified Lactobacillus sp., was similar in ac- cordance with those earlier identified in different environments, suggested by Beasley (2004). The oil displacement test is an indirect measurement of surface activity of bio surfactants: a larger clear area is correlated with higher surface activity (Plaza et al., 2006). The drop collapse method is based on the principle that a drop of liquid containing a bio surfactant collapses and spreads over the oily surface. There is a right

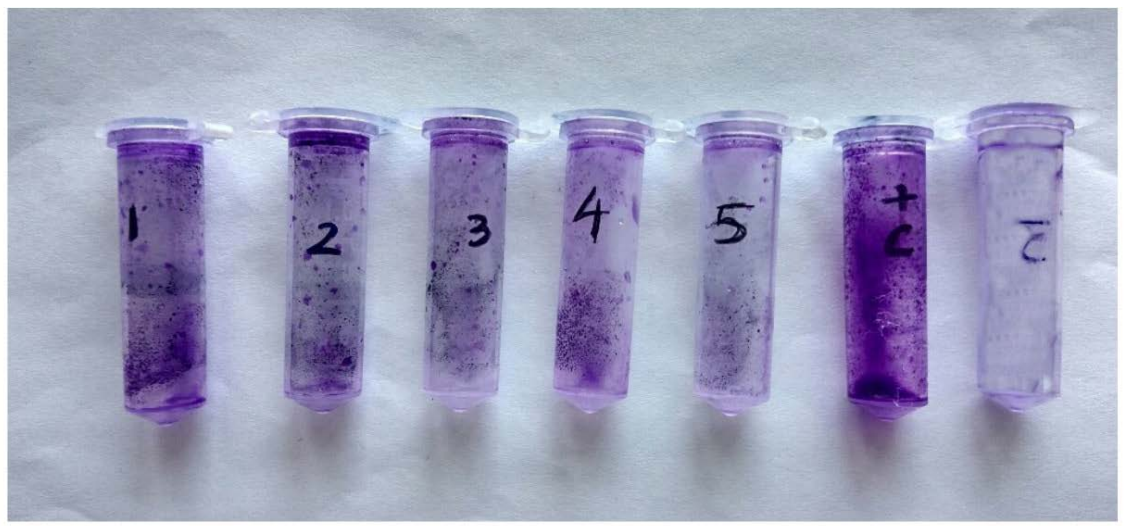

(1) $-10 \%,(2)-20 \%,(3)-30 \%,(4)-40 \%$ and $(5)-50 \% \mathrm{v} / \mathrm{v}$.

Positive control - untreated microfuge and negative control - microfuge with crystal violet.

Fig. 6. E.coli culture treated with biosurfactant at different concentrations.

(1) $-10 \%,(2)-20 \%,(3)-30 \%$, (4) $-40 \%$ and $(5)-50 \%$ v/v.

Positive control - untreated microfuge and negative control - microfuge with crystal violet. 
away relationship between the diameter of the sample and concentration of the biosurfactant and in distinction, the drop lacking biosurfactant remains beaded thanks to the hydrophobicity of the oil surface that causes aggregation of droplets. The molecular composition of the crude biosurfactant was evaluated by FTIR, and TLC that disclosed the presence of polysaccharides and lipid together (Lipopeptide). Similar peaks for functional groups were additionally allotted to the biosurfactant obtained from Lactococcus lactis. Proton NMR of Lactococcus lactis additionally showed the similar peaks for arrangement of atom (Saravanakumari and Mani, 2010). The microorganism strains that created microcolonies on the glass surface were characterised by a special level of adhesion to polymer. The link between property of the atmosphere surface and outer membrane of a selected strain in biofilm formation and surface (polyurethane, glass) are often related to hydrophobic microorganism (Krasowska \& Sigler, 2014). Ninhydrin chemical agent disclosed the presence of liopeptide compound within the biosurfactant extracted from eubacterium as red spots, this can be quite contrastive to earlier reports on antimicrobial actions of the biosurfacants wherever the lipopeptide biosurfactants are reported to move principally against most of the microorganism (Singh and Cameotra, 2004). The antibiogram of the isolated strains secreting biosurfactants were shown to own numerous antibiotic resistance profiles, indicating their diversity and condition in numerous conditions.

\section{CONCLUSION}

Bacteria survive in nature and form biofilm on different surfaces. Bacterial biofilms are hot beds of antimicrobial resistance. The bacteria emerge resistant to most of the antibiotics, disinfectant chemicals and to phagocytosis and other components of the innate and adaptive inflammatory defense system of the body. Biofilms harbour human infectious agents, E.coli is a predominant species found in the human gastrointestinal tract and has the capacity to form biofilm in vivo and in vitro.

Lactobacillus being a probiotic bacterium has a potential interfering bacteria by producing various antimicrobial agents. The use of biosurfactant is a biologically derived active end product over the chemical surfactant. The results of the biofilm inhibition assays suggest that the biosurfactant produced has an inhibitory effect on biofilm of E.coli. This study demonstrates that the lipopeptide biosurfactant produced has a potential future application in environmental remediation, food industry and also in medical uses to combat diseases.

\section{ACKNOWLEDGEMENTS}

None

\section{CONFLICT OF INTERESTS}

The authors declare that there are no conflict of interest.

\section{REFERENCES}

1. Abdullahi Adamu, Udeme J.J.Ijah, Maeryam L.Riskuwa,Haruna Y.Ismail, Umar B. Ibrahim. Study on biosurfactant production by two Bacillus species. International Journal of scientific research in knowledge, 2015; 3(1).pp.013-020.

2. Altschul Stephen, F., Thomas, L., Madden, A., Alejandro Schaffer, Jinghui Zhang, Zheng Zhang, Webb Miller David, Lipman, J. Gapped BLAST and PSI-BLAST A new generation of protein database search programs. Nucleic Acids Res., 1997; 25: 3389-3402

3. Anayata Sharma, Jitesh Soni,Gurveer Kaur,Jaspreet Kaur. A study on biosurfactant production in Lactobacillus and Bacillus sp. International Journal of current Microbiology and Applied Sciences, 2014; 3(11).723-733

4. ArezooTabmourespour, Rasoul Salchi, Rooha Kasra, Kermanshashi. Lactobacillus acidophilus-derived biosurfactant effect on GTFB and GTFC expression level in Streptococcus mutans biofilm cells. Brazillian Journal of Microbiology, 2011; 42:330-339

5. Ausubel, F.M., Brent, R., Kingston, R.E., Moore, D.D., Seidelman,Struhl, J .G. Current protocols in molecular biology. John Wiley and Sons, New York, 1988.

6. Beasley S. Isolation, identification and exploitation of lactic acid bacteria from human and animal microbiota. Helsinky: University of Helsinki, 2004.

7. Characklis WG.Attached microbial growths-II. Frictional resistance due to microbial slimes. Water Res., 1973; 7:1249-58

8. Flemming HC, Wingender J, Griegbe, Mayer C. Physicochemical properties of biofilms. In: Evans LV, editor. Biofilms: recent advances in their study and control. Amsterdam: Harwood Academic Publishers, 2000; p. 19-34.

9. Gupta V, Garg R. Probiotics. Indian J Med Microbiol., 2009; 27:202-209.

10. Hawthorn LA, Reid G. Exclusion of uropathogen adhesion to polymer surfaces by Lactobacillus acidophilus. J Biomed Mater Res., 1990; 24:39-46.

11. Holt, J.G., N.R. Kreig, P.H.A. Sneath, J.T. Staley and S.T. Williams: Bergey's manual of determinative 
bacteriology 9th Edn. Williams and Wilkins, Maryland, USA, 1994.

12. Jayaraman A, Mansfeld FB, Wood TK. Inhibiting Sulfate-Reducing Bacteria in Biofilms by Expressing the Antimicrobial Peptides Indolicidin and Bactenecin. J. Indust. Microbiol. Biotechnol., 1999; 22:167-175.

13. Jones HC, Roth IL, Saunders WM. III Electron microscopic study of a slime layer. J Bacteriol., 1969; 99:316-25

14. Krasowska A, Sigler K. How microorganisms use hydrophobicity and what does this mean for human needs? Front Cell Infect Microbiol., 2014; 4: 112.

15. Plaza GA, Zjawiony I, Banat IM. Use of methods for detection of thermophilic biosurfactant-producing bacteria from hydrocarbon-contaminated and bioremediated soils. J. Petrol Sci. Eng., 2006; 50:71-77.

16. Pratt LA, O'Toole GA, Watnick PI, Newman DK, Weaver VB, Kolter R. Genetic approaches to study of biofilms. Methods Enzymol., 1999; 310:91-109.

17. Probert HM, Gibson GR. Bacterial biofilms in the human gastrointestinal tract. Curr Issues Intest Microbiol., 2002 3:23-27.

18. Ragavendran, P., Sophia, D., Arul Raj, C., \& Gopalakrishnan, V. K. Functional group analysis of various extracts of Aerva lanata (L.,) by FTIR spectrum. Pharmacology-online, 2011; 1: 358-364.

19. Rodrigues LR, Teixeira JA, van der Mei HC, Oliveira R. Physicochemical and functional characterization of a biosurfactant produced by Lactococcus lactis 53 . Colloids Surf B Biointerfaces., 2006; 49:79-86.

20. Saravanakumari P. and Mani K., Structural characterization of a novel xylolipid biosurfactant from Lactococcus lactis and analysis of antibacterial activity against multi-drug resistant pathogens, Bioresource Technology, 2010; 101(22):8851-8854,

21. Singh P, Cameotra SS. Potential applications of microbial surfactants in biomedical sciences. Trends Biotechnol., 2004; 22:142-146.

22. Sutherland IW. Biofilm exopoly-saccharides: a strong and sticky framework. Microbiology., 2001; 147:3-9.

23. Tuvell M. E., Kuehnhans S G. O., Heidebrecht G. D. ,Hu P. C. ,Zielinski A. D. AOS - An anionic surfactant system: Its manufacture, composition, properties, and potential application. Journal of American Oil Chemists Society, 1978; 55(1): 70-80

24. Velraeds MCM, van der Mei HC, Reid G, Busscher HJ. Physicochemical and biochemical characterization of biosurfactants released by Lactobacillus strains. Colloids Surf B Biointerfaces, 1996; 8:51-61.

25. Willumsen PA, Karlson U. Screening of bacteria, isolated from PAH contaminated soils, for production of biosurfactants and bioemulsifiers. Biodegradation, 1997; 7: 415-423.

26. Zobell CE. The effect of solid surfaces on bacterial activity. J Bacteriol., 1943; 46:39-56. 